\title{
CARACTERIZAÇÃO DA PRECIPITAÇÃO PLUVIOMÉTRICA DA BACIA DO RIO PIQUIRI (PR) - 1979 A 2012
}

\author{
PIRES, Regis Aparecido de Souza - raspires@outlook.com \\ Universidade Estadual de Maringá / UEM
}

\begin{abstract}
RESUMO: O presente trabalho tem como objetivo caracterizar a variabilidade da precipitação pluviométrica da bacia hidrográfica do Rio Piquiri. Utilizou-se de dados de 51 postos pluviométricos obtidos através do Instituto das Águas do Paraná (Águas Paraná) para o período de 1979 - 2012. Verificando a distribuição e a variabilidade espaçotemporal da precipitação pluviométrica, através da geração de mapas de isoietas. A bacia hidrográfica do rio Piquiri está inserida dentro do Estado Paraná entre as coordenadas geográficas $23^{\circ} 30^{\prime} 00^{\prime \prime}$ e $25^{\circ} 30^{\prime} 00^{\prime \prime}$ latitude sul e $51^{\circ} 30^{\prime} 00^{\prime \prime}$ e $54^{\circ} 30^{\prime} 00^{\prime \prime}$ de longitude oeste do Meridiano de Greenwich. Neste trabalho foram analisados os dados de precipitação pluvial em diversas escalas (anual, sazonal, mensal e diária). Através da análise da estatística descritiva foram gerados mapas de isoietas de desvio padrão, coeficiente de variação, média e anomalias. A variabilidade da precipitação pluviométrica na bacia hidrográfica do rio Piquiri, tem uma relação direta com os fenômenos El Niño e La Niña, a qual foi possível observar anomalias positivas (eventos El Niño) na qual foram observados quatro anos mais chuvosos (1982, 1983, 1992 e 1998) e anomalias negativas (eventos La Niña) que se fez possível perceber os quatro anos mais secos do período analisado (1985, 1988, 1999 e 2012). Foi percebido também a marcante diferença entre o centro-sul e sudeste em confronto ao norte e noroeste da bacia, em que as variações espaciais com os maiores totais foram observadas na primeira porção, ao passo que os menores totais na outra porção da bacia.
\end{abstract}

PALAVRAS-CHAVE: bacia hidrográfica, rio Piquiri, precipitação pluvial, variabilidade pluviométrica.

\section{CHARACTERIZATION OF RAINFALL PRECIPITATION IN THE RIVER BASIN PIQUIRI (PR) - 1979 A 2012}

ABSTRACT: The present work aims to characterize the variability of rainfall precipitation in the river basin Piquiri. It used data from 51 rain gauges obtained through the Institute of Paraná Waters (Águas Paraná) for the period 1979 - 2012. Checking the distribution and the spatial and temporal variability of rainfall, by generating isohyets maps. The catchment area of the river Piquiri is inserted into the Paraná State between the geographical coordinates $23^{\circ} 30^{\prime} 00$ " and $25^{\circ} 30^{\prime} 00^{\prime \prime}$ south latitude and $51^{\circ} 30^{\prime} 00^{\prime \prime}$ and $54^{\circ} 30^{\prime} 00$ " of west longitude of Greenwich Line. In this study we analyzed the rainfall data at various scales (annual, seasonal, monthly and daily). Through the analysis and statistics, were generated isohyets maps of pattern deviation, coefficient of variation, average and anomalies. The variability of rainfall in the catchment area of the Piquiri River, has a direct relationship with El Niño and La Niña, which we observed positive anomalies (El Niño) which were observed four years rainiest (1982, 1983, 1992 and 1998) and negative anomalies (events La Niña) that made it possible to realize the four driest years of the analyzed period (1985, 1988, 1999 and 2012). It was also perceived a marked difference between the south-central and southeast in comparison to the north and northwest of the basin, where the spatial variations with the largest total were observed in the first portion, whereas the total smaller in the other portion of the basin.

KEYWORDS: watershed, river Piquiri , rainfall , rainfall variability 

PIQUIRI (PR) - 1979 A 2012

RESUMEN: El presente trabajo tiene como objetivo caracterizar la variabilidad de la precipitación pluviométrica de la cuenca hidrográfica del Río Piquiri. Se utilizó datos de 51 puestos pluviométricos obtenidos a través del Instituto de las Aguas de Paraná para el período de 1979 a 2012. Verificando la distribución y la variabilidad espacio-temporal de la precipitación pluviométrica, a través de la generación de mapas de isoietas. La cuenca hidrográfica del río Piquiri está inserta dentro del Estado Paraná entre las coordenadas geográficas $23^{\circ} 30^{\prime} 00^{\prime \prime}$ y $25^{\circ} 30^{\prime} 00$ " latitud sur y $51^{\circ} 30^{\prime} 00^{\prime}$ y $54^{\circ} 30^{\prime} 00$ " longitud oeste del meridiano de Greenwich. En este trabajo se analizaron los datos de precipitación pluvial en diversas escalas (anual, estacional, mensual y diaria). A través del análisis de la estadística descriptiva se generaron mapas de isoietas de desviación estándar, coeficiente de variación, media y anomalías. La variabilidad de la precipitación pluviométrica en la cuenca hidrográfica del río Piquiri, tiene una relación directa con los fenómenos El Niño y La Niña, la cual fue posible observar anomalías positivas (eventos El Niño) en la cual se observaron cuatro años más lluviosos (1982, 1983, (1992 y 1998) y anomalías negativas (eventos La Niña) que se hizo posible percibir los cuatro años más secos del período analizado $(1985,1988,1999$ y 2012). Se percibió también la marcada diferencia entre el centro-sur y sureste en confrontación al norte y noroeste de la cuenca, en que las variaciones espaciales con los mayores totales se observaron en la primera porción, mientras que los menores totales en la otra porción de la cuenca.

PALABRAS CLAVE: cuenca hidrográfica, río Piquiri, precipitación pluvial, variabilidad pluviométrica

\section{INTRODUÇÃO}

Barrella (2001) define bacia hidrográfica como um conjunto de terras delimitadas por divisores de água nas regiões mais altas do relevo, drenadas por um rio e seus afluentes, em que as águas pluviais, ou escoam superficialmente formando os riachos e rios, ou infiltram no solo para formação de nascentes e do lençol freático, tal que toda vazão efluente seja descarregada por uma simples saída.

Ao analisar as características do clima de uma bacia hidrográfica, principalmente a precipitação, adquire-se importante conhecimento para subsidiar o planejamento de todas as atividades existentes dentro de uma bacia, Correa (2013), além de ser, junto com outros fatores, um dos elementos essenciais para a definição do tipo de vegetação é também de suma importância para a gestão do território bem como suas práticas agrícolas e uso e ocupação da terra.

Portanto, a precipitação pluviométrica é um dos mais importantes elementos meteorológicos, principalmente nas regiões tropicais. "Todo um conjunto de atividades, entre elas os agrícolas, das quais tantas outras dependem, estão estreitamente associadas ao regime pluvial, sendo gravemente prejudicadas pelos episódios extremos, como as secas ou as enchentes" (BALDO, 2006).

Desta forma estudar a quantificação pluvial e sua distribuição temporal e espacial servem de subsídios para a tomada de decisões no que se refere ao planejamento das áreas urbana e agrícola, tal como o planejamento adotado para o conservacionismo das bacias hidrográficas.

Diante desta perspectiva, o trabalho tem por objetivo caracterizar a precipitação pluviométrica dentro da bacia hidrográfica do rio Piquiri, no Estado do Paraná, no período de 1979 a 2012. Levando em consideração a importância 
da identificação dos períodos chuvosos para gestão do território bem como suas práticas agrícolas e uso e ocupação da terra inserida na bacia hidrográfica estudada.

\section{MATERIAL E MÉTODOS}

A bacia hidrográfica do Rio Piquiri, doravante BHRP, é a terceira maior em área física do Estado do Paraná, no qual o Rio Piquiri atravessa a extensão da bacia no sentido sudeste - centro-oeste, sendo sua foz no Rio Paraná, com uma área de drenagem de aproximadamente $24.156 \mathrm{~km}^{2}$ (SEMA, 2010), localiza-se inteiramente dentro do estado paranaense com cerca de $12 \%$ da área do estado contendo 69 municípios e com uma população que segundo o Censo de 2010 se aproxima de 1.504,948 habitantes e com estimativa para 2015 de $1.587,393$ habitantes, a bacia está entre as coordenadas geográficas de $23^{\circ} 30^{\prime} 00^{\prime \prime}$ e $25^{\circ} 30^{\prime} 00^{\prime \prime}$ latitude sul e $51^{\circ} 30^{\prime} 00^{\prime \prime}$ e $54^{\circ} 30^{\prime} 00^{\prime \prime}$ de longitude oeste (Figura 1).

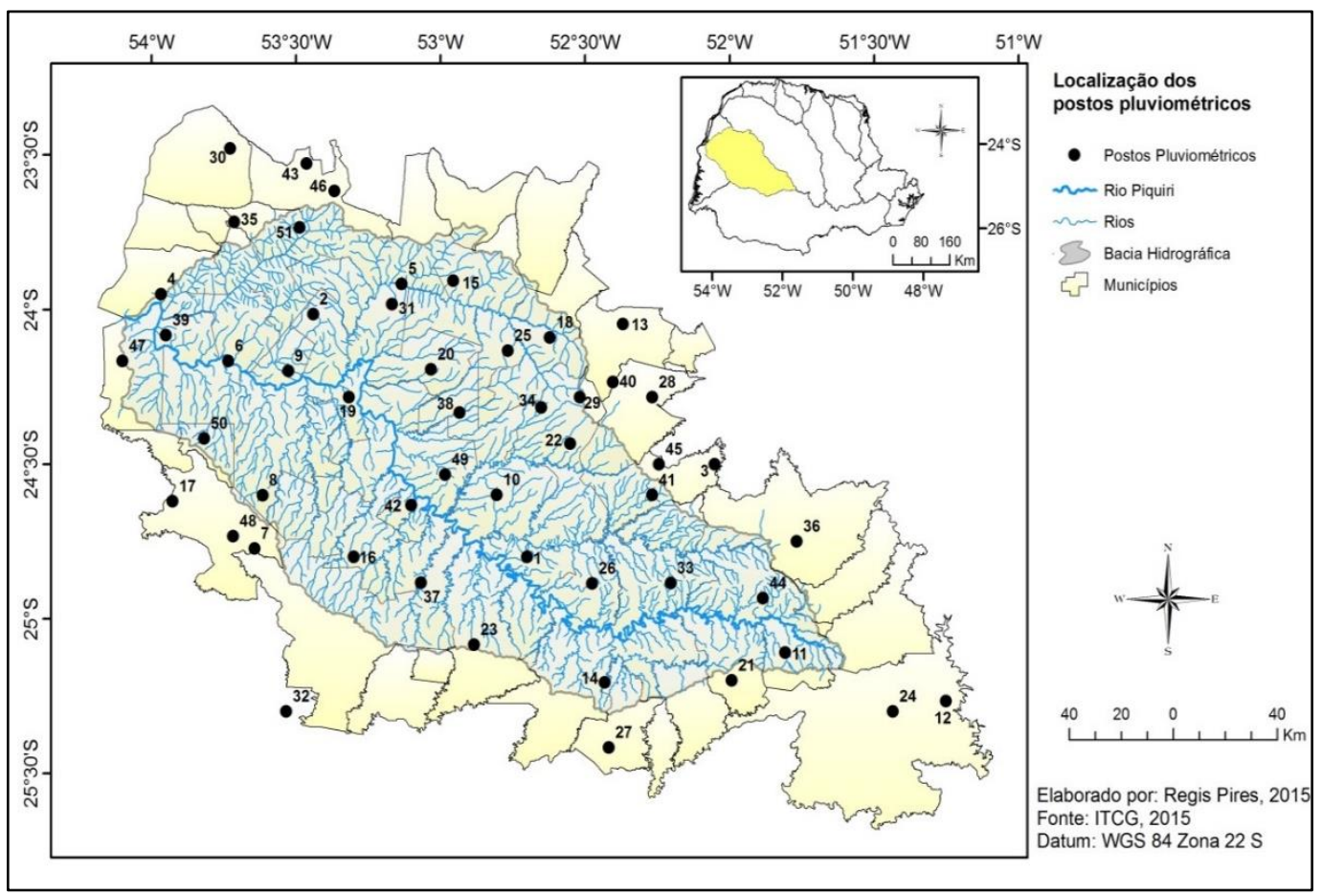

Figura 1 - Localização dos postos pluviométricas na Bacia Hidrográfica do Rio Piquiri PR.

\section{OBTENÇÕES DOS DADOS PLUVIOMÉTRICOS}

A aquisição dos dados de precipitação pluviométrica deu-se junto ao Instituto de Águas do Paraná. Inicialmente foram obtidos dados diários de 161 estações dentro e extra bacia hidrográfica do Rio Piquiri, dessas realizou-se uma filtragem dos dados mais consistentes no qual resultou uma quantia de 51 postos com uma série histórica de coleta de dados de 33 anos compreendida entre o período de 1979-2012. 
Baseando-se nos dados da série histórica, realizou-se a aplicação da estatística descritiva para todos os postos, fazendo o uso dos diversos parâmetros estatísticos dos quais: média, mediana, desvio padrão, coeficiente de variação, máxima, mínima e amplitude. Esses métodos foram realizados por meio de planilha de cálculo Excel e também com a utilização do software Statistica para a geração dos grupos homogêneos. Na etapa seguinte utilizou-se do software Surfer para a geração dos mapas de isolinhas, em que para cada parâmetro foi utilizado um semivariograma ajustados ao modelo power, fazendo-se o uso do interpolador Kriging, o qual apresentou uma melhor distribuição espacial da variável precipitação pluviométrica.

Para determinar as áreas homogêneas, foram utilizados 30 postos dentro do limite da bacia, em que se obteve 4 grupos que apresentaram similaridade no padrão pluviométrico. Foi utilizado o método de Ward, que consiste em formar grupos de dados buscando minimizar a soma das diferenças entre os elementos de cada grupo e o valor médio do grupo, minimizando o desvio padrão entre os dados de cada grupo formado ,com distância euclidiana para a obtenção do dendograma (figura 2).

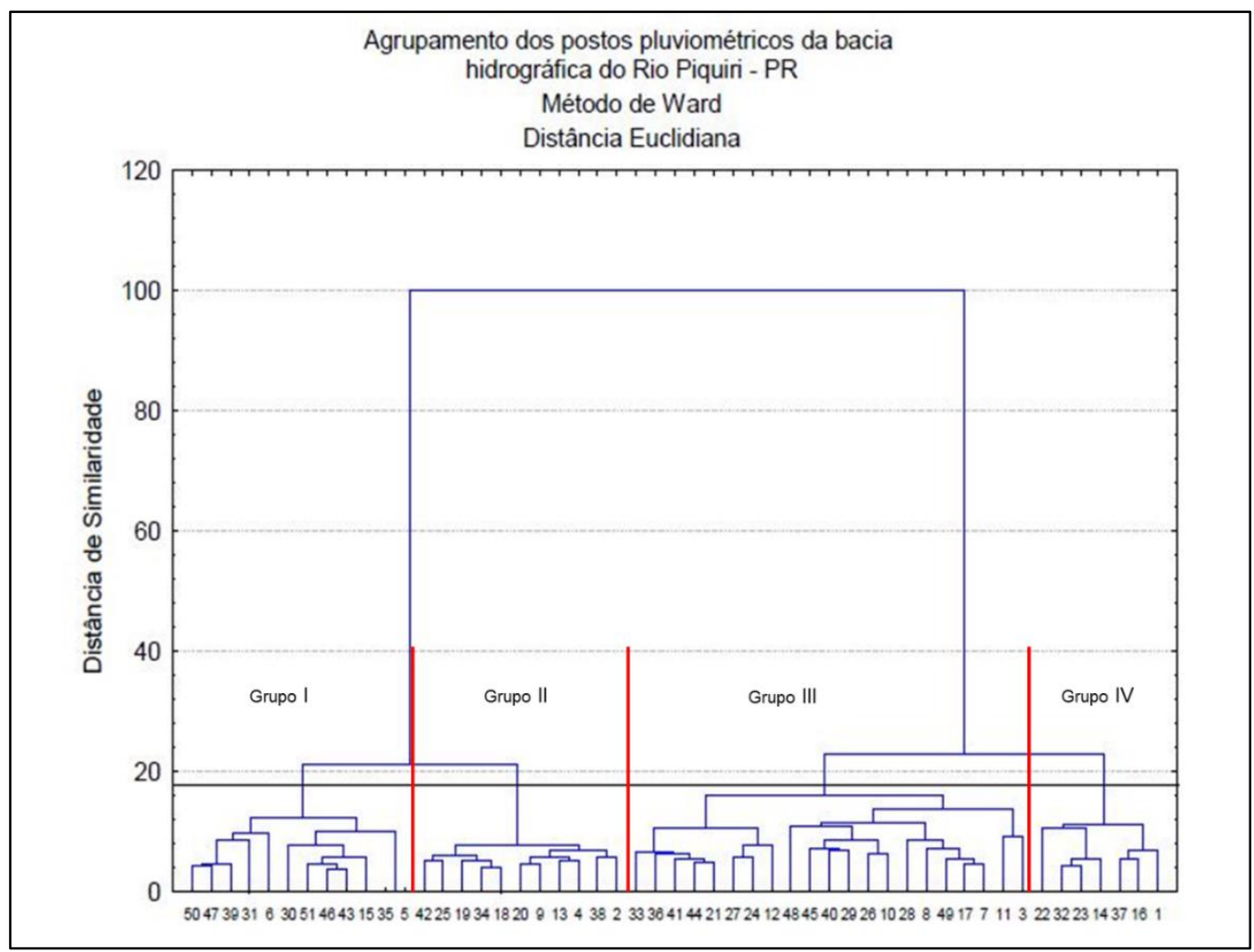

Figura 2 - Dendograma de obtenção dos grupos homogêneos da bacia hidrográfica do rio Piquiri - PR.

A partir dos dados de todas as estações, foi realizado o agrupamento das áreas homogêneas dentro da bacia hidrográfica do rio Piquiri, a figura 3 ilustra como estão distribuídos os grupos. Nota-se que há estações fora da bacia 
hidrográfica, as quais foram utilizadas para realização da interpolação dos dados pluviométricos de forma a ter uma melhor representatividade das isoietas, porém para a análise do Índice de anomalia de chuva foram utilizadas somente 30 estações dentro do limite da bacia, em que se obteve 4 grupos que apresentaram similaridade no padrão pluviométrico.

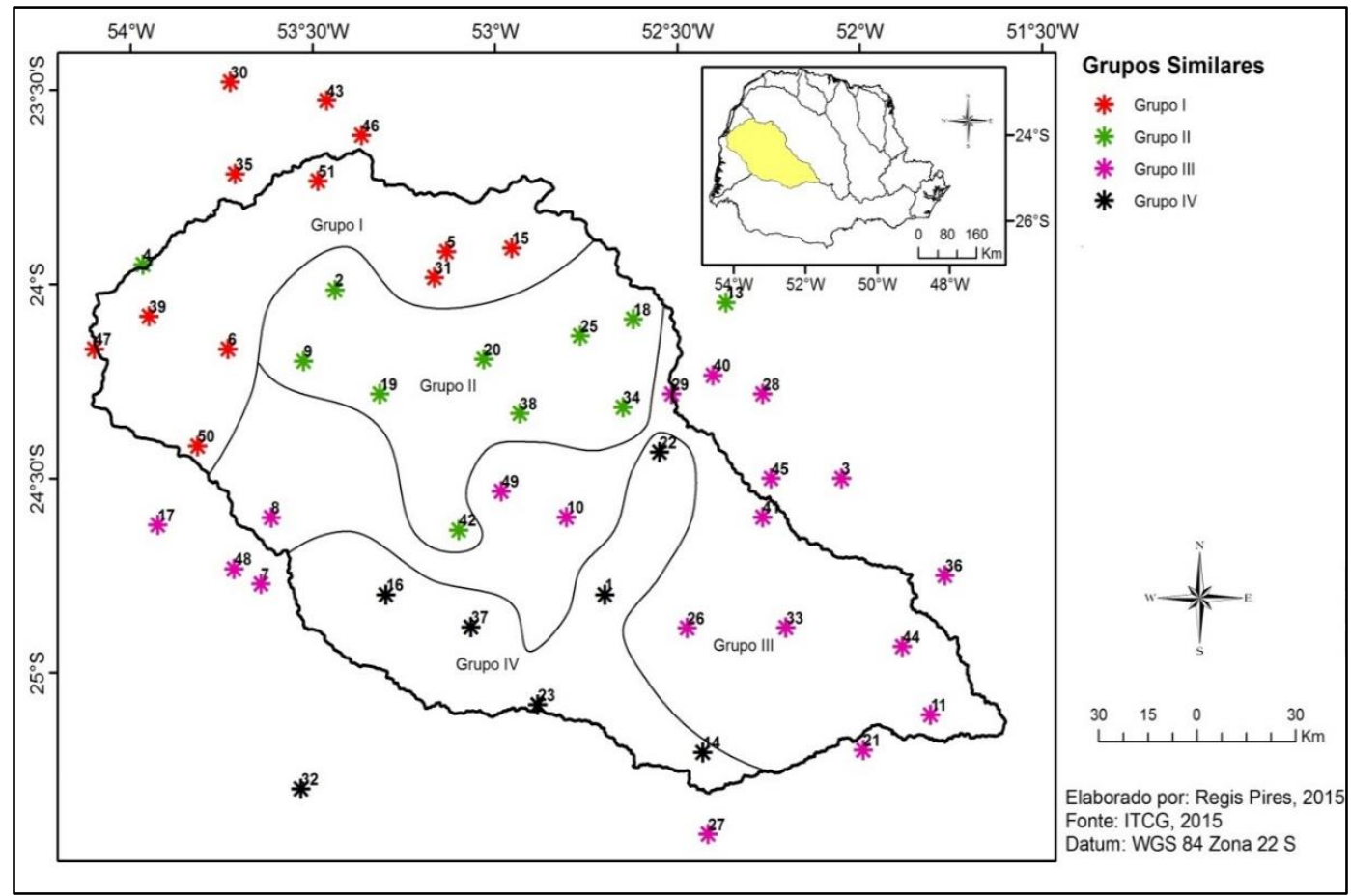

Figura 3 - Localização dos grupos homogêneos na bacia hidrográfica do rio Piquiri - PR.

Foi utilizada a equação de anomalia (Xi - Xm) para cada ano civil da série estudada e para todas as estações. Sendo que Xi é o valor anual da precipitação observada e Xm representa o valor médio anual de período.

Para a determinação dos anos considerados atípicos, optou-se por utilizar a metodologia desenvolvida por Rooy (1965), através do Índice de Anomalia de Chuva (IAC), que consiste da determinação de anomalias extremas, que segundo o autor, o índice visa tornar o desvio da precipitação em relação à condição normal de diversas regiões passiveis de comparação, associado a nove classes de IAC. O método para o cálculo pode ser visto nas equações 1 e 2:

$I A C=3\left[\frac{(P-P m)}{x-P m}\right]$

$I A C=-3\left[\frac{(P-P m)}{y-P m}\right]$

Em que, IAC é o índice de anomalia de chuva; $\mathrm{P}$ é a precipitação observada $(\mathrm{mm}) ; \mathrm{Pm}$ é a precipitação média $(\mathrm{mm}) ; x$ representa a média dos dez valores mais altos e y corresponde à média dos dez valores mais baixos. 
Adotaram-se para anomalias positivas e negativas valores acima e abaixo da média, relativamente da série histórica do estudo deste trabalho, para tal, se fez o emprego da classificação dos anos secos e úmidos de acordo com a classificação do índice de anomalia de precipitação (Rooy, 1965) como pode ser vista na tabela 1.

Tabela 1 - Classificação do Índice de Anomalia de Precipitação

\begin{tabular}{|c|c|}
\hline IAC & CLASSIFICAÇÃO \\
\hline$\geq 4,00$ & Extremamente úmido \\
\hline 3,00 a 3,99 & Umidade alta \\
\hline 2,00 a 2,99 & Umidade moderada \\
\hline 0,5 a 1,99 & Umidade baixa \\
\hline$-0,49$ a 0,49 & Normal \\
\hline$-1,99$ a $-0,50$ & Seca suave \\
\hline$-2,00 a-2,99$ & Seca moderada \\
\hline$-3,00 a-3,99$ & Seca alta \\
\hline$\leq-4,00$ & Extremamente seca \\
\hline
\end{tabular}

Fonte: Rooy (1965).

\section{DISCUSSÃO DOS RESULTADOS}

\section{ANÁLISE DA ESCALA ANUAL}

O clima da Região Sul do Brasil retrata grandes disparidades nos regimes de precipitação e temperatura. Segundo Grimm et al (2009), isso se deve à situação geográfica do relevo, localizado na transição entre os trópicos e as médias latitudes, com um relevo acidentado contribuindo para a ocorrência desses contrastes. A autora ainda salienta que os efeitos da topografia do relevo exercem uma grande influência, uma vez que as maiores precipitações estão associadas à ascensão sobre a barreira topográfica. Diante dessa perspectiva, Sousa (2006) destaca que o Estado do Paraná, apresenta valores elevados de precipitação pluviométrica, em todo o território paranaense.

De acordo com Pelegatti e Galvani (2010), a associação do tipo de sistema atmosférico e o posicionamento da vertente acentuam a orografia, sendo assim, associado a sistemas atmosféricos juntamente com o relevo, 0 resultado dos valores anuais totais da precipitação pluviométrica na bacia hidrográfica do Rio Piquiri mostrou uma significativa variabilidade espacial da pluviosidade média anual variando entre $1400 \mathrm{~mm}$ a $2045 \mathrm{~mm}$. O qual o Alto 
Piquiri, assume os maiores valores médios anuais de chuva (acima de 1900 $\mathrm{mm}$ ), onde ocorrem as maiores cotas altimétricas acima dos 1100 metros. Já na parte do Baixo Piquiri, a pluviosidade média anual é menor, assumindo valores abaixo dos $1500 \mathrm{~mm}$, conforme pode ser visualizado na figura 4.

Setzer (1946) explana sobre as condicionantes geográficas (cobertura vegetal, solo e relevo) atuantes na variabilidade pluvial no Estado de São Paulo, ficando evidente a correlação entre a altimetria do terreno e o direcionamento das massas de ar na distribuição pluviométrica daquele Estado.

Milanesi e Galvani (2011) advertem que, de forma geral, observa-se que independentemente do porte do relevo, este exerce algum notável controle sobre as dinâmicas climáticas locais. Nesse contexto se tem a ocorrência dos efeitos orográficos, uma vez que na porção mais alta da bacia tem-se uma maior concentração da pluviosidade, à proporção que, paulatinamente os valores pluviométricos sofrem uma diminuição no sentido da jusante.

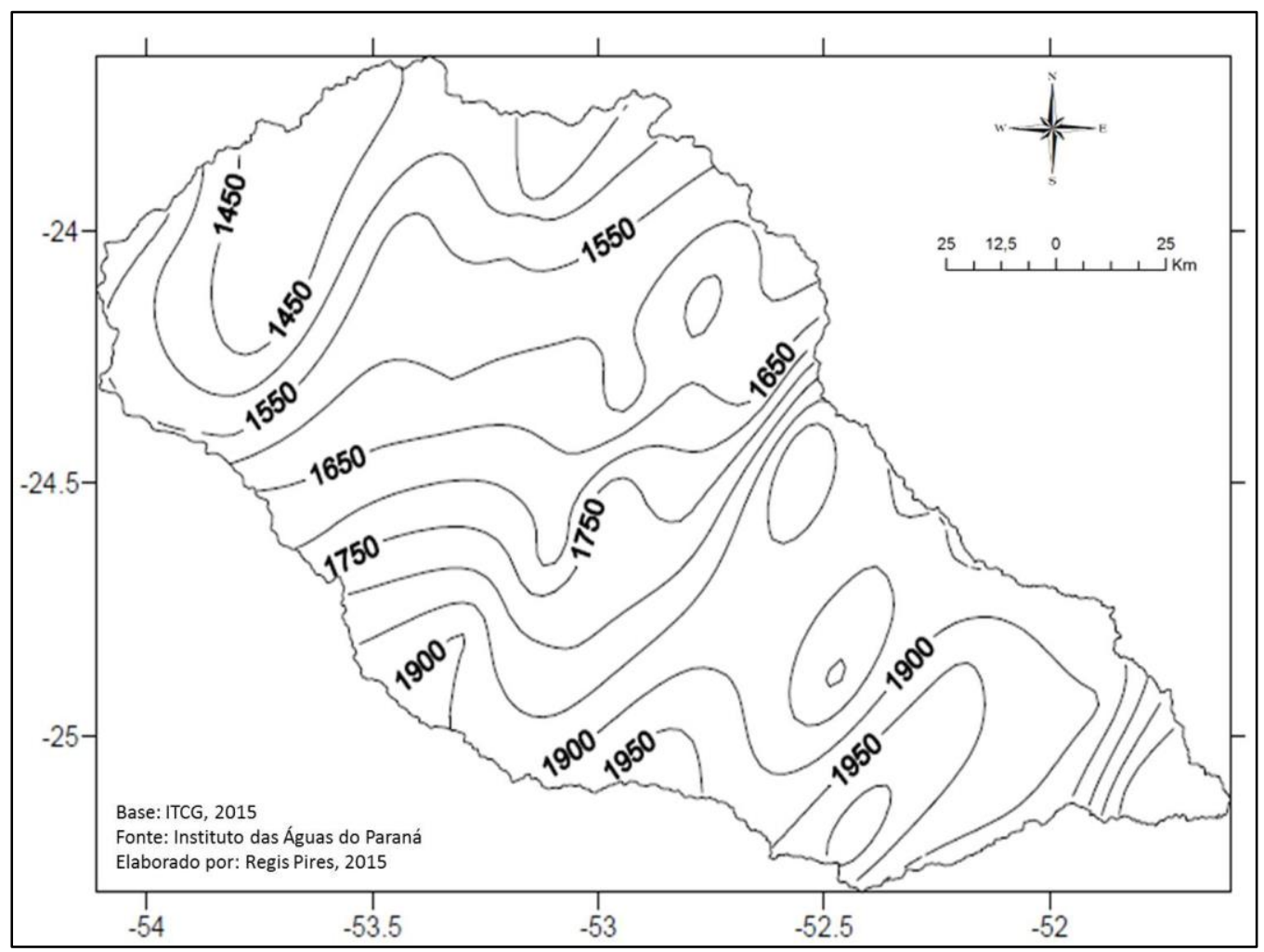

Figura 4 - Precipitação Média Anual na Bacia Hidrográfica do Rio Piquiri - PR

Quando observado os valores médio anual dos dias de chuva na BHRP, os resultados que se tem referente aos dados primários das estações meteorológicas propiciam o entendimento da regularidade do número de dias de chuva na bacia. A figura 5 retrata a escala anual apresentando dois padrões distintos, sendo o relevo um dos fatores responsáveis por essa distribuição, na porção situado a montante a média dos dias de chuva superam os 103, na medida em que se distancia da montante, tem-se uma ligeira redução desses 
valores, no setor central da bacia entre 88 a 96 dias de chuva e por fim, a jusante da bacia, o número médio está entre 80 a 85 dias que ocorreram a precipitação pluviométrica.

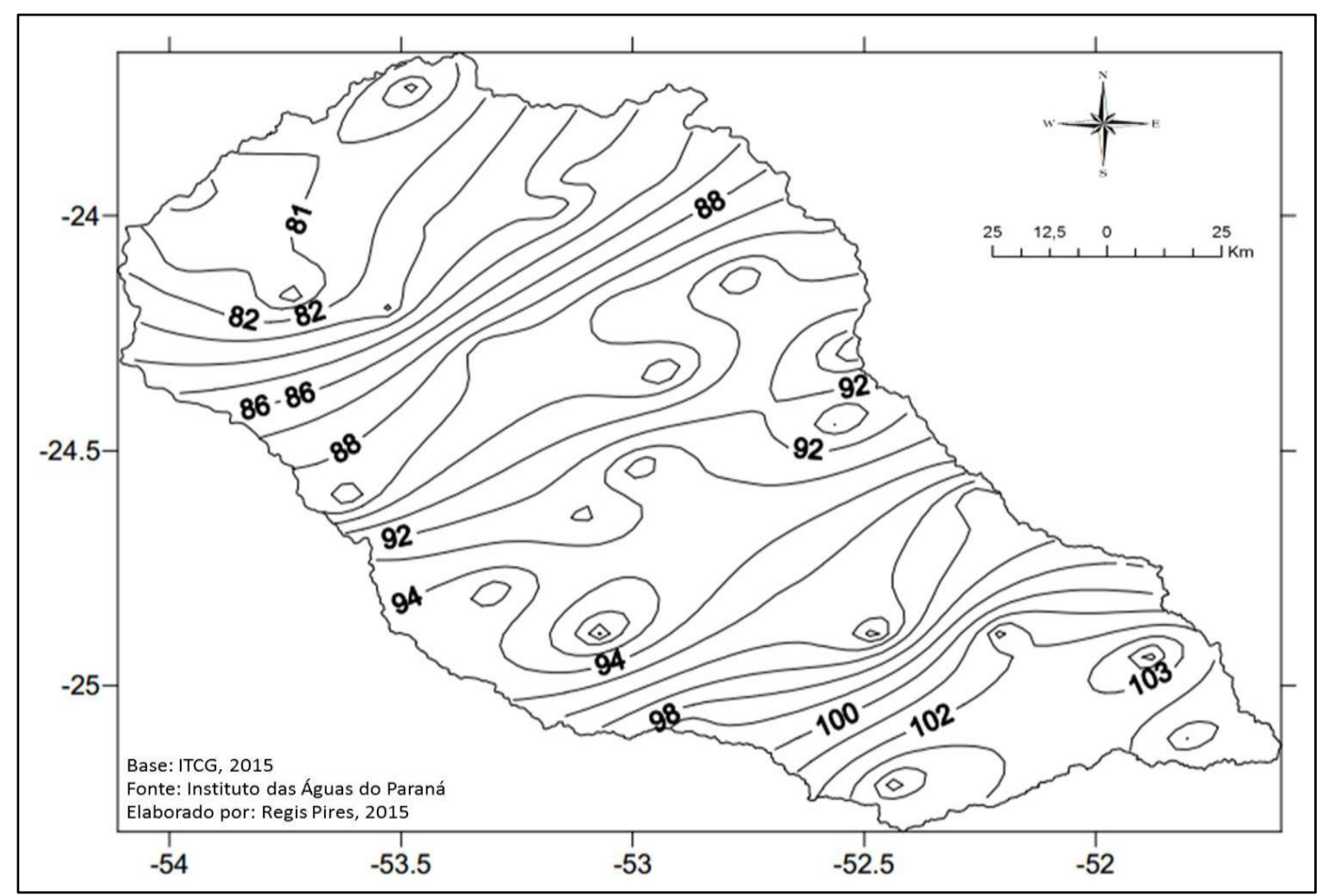

Figura 5 - Isolinhas de números médios dos dias de chuva anual para o período de 1979 $-2012$.

\section{ANÁLISE DA ESCALA MENSAL}

A observação da escala mensal dos valores médios de precipitação pluviométrica na bacia hidrográfica do rio Piquiri (figura 6), dá uma ideia de como está distribuída a chuva (desconsiderando a distribuição espacial na área estudada). Os meses em que se verificou os maiores volumes pluviométricos foram outubro $(198,74 \mathrm{~mm})$, janeiro $(185,70 \mathrm{~mm})$ e dezembro $(182,93 \mathrm{~mm})$ à medida que os meses de junho $(119,73 \mathrm{~mm})$, julho $(97,39 \mathrm{~mm})$ e agosto $(82,62$ $\mathrm{mm}$ ) foram considerados como os de menores valores de precipitação. Para os meses de maio e outubro se tem o aumento dos valores de precipitação devido à transição entre estações. 


\section{Precipitação pluviométrica $(\mathrm{mm})$}

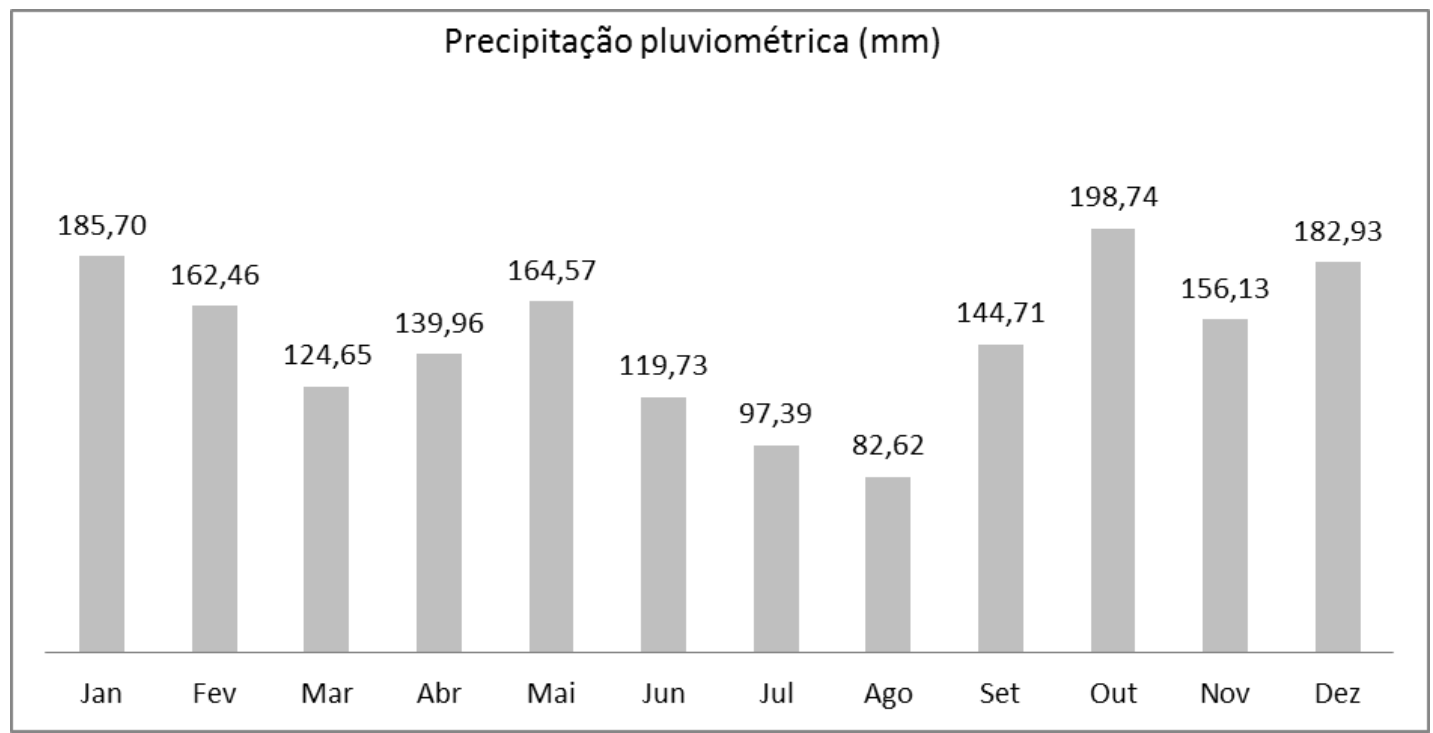

Figura 6 - Distribuição mensal da pluviosidade média na bacia hidrográfica do rio Piquiri para o período de 1979 - 2012.

No sul da Itália, por meio de um índice de concentração das chuvas, Coscarelli e Caloiero (2012) analisaram a distribuição das chuvas e observaram a importância de buscar a compreensão da quantidade de dias chuvosos na distribuição anual da precipitação, buscando o entendimento dos riscos de inundações e da instabilidade dos solos. Na figura 7 tem-se a média da frequência de dias de chuva para cada mês, nota-se que os meses com os maiores valores registrados foram janeiro $(10,41$ dias), fevereiro $(9,88)$, dezembro ( 9,35 dias) e outubro ( 9,13 dias), enquanto os menores valores foram observados nos meses de agosto (4,79 dias), julho (5,66 dias) e junho $(6,16$ dias $)$

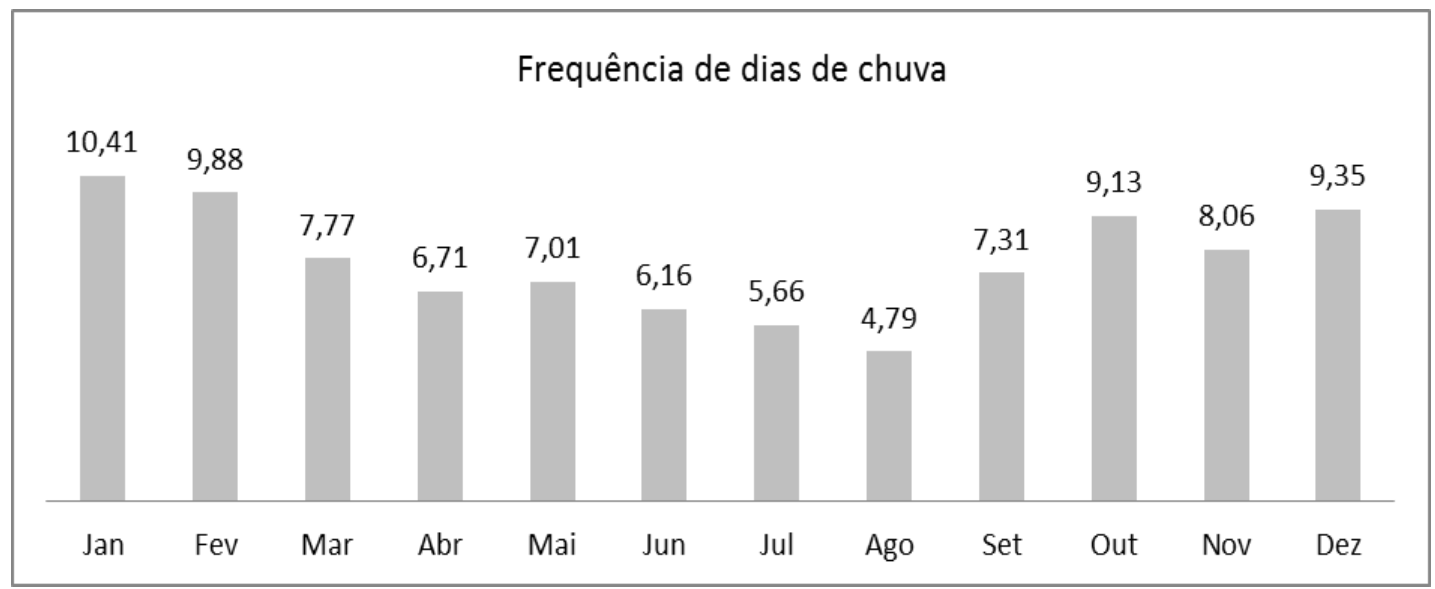

Figura 7 - Frequência de dias de chuva na bacia hidrográfica do rio Piquiri para o período de $1979-2012$. 


\section{ANÁLISE DOS ANOS ANÔMALOS}

O fenômeno El Niño é um fenômeno oceânico que ocorre interanualmente, sua interação oceano-atmosfera origina o El Niño Oscilação Sul (ENOS), tal fenômeno, segundo Weykamp (2006) tem influenciado nas condições climáticas no Brasil, principalmente na Região Sul, em especial nos valores pluviométricos. Esse evento gera anomalias climáticas não só no Brasil, mas em todo o globo terrestre.

Para Grimm (2009), o fenômeno ENOS corresponde à oscilação entre o oceano e a atmosfera, em que há a alteração da Temperatura da Superfície do Mar (TSM), a pressão atmosférica, o vento e a convecção tropical. Para este trabalho não foi realizado a análise da correspondência da precipitação com os índices da TSM, uma vez que o propósito é apresentar os anos secos e os anos chuvosos.

Dentro do período de estudos, para o INPE (online), os anos considerados mais secos foram 1988-1989, 2007-2008, considerados como secos moderados foram 1983-1984, 1984-1985, 1995-1996. Para os anos mais chuvosos temos 1982-1983, 1990-1993, 1997-1998,

Neste trabalho foi considerado como anos secos, aqueles com índices de anomalias de seca alta a extremamente seca e os anos chuvosos com índices entre umidade alta a extremamente úmido, através dos dados de todas as estações analisados subjetivamente, buscando eleger os anos com as características citadas anteriormente, como resultados obtidos, tem-se como anos mais secos do período 1985, 1988, 1999 e 2012 e os anos mais chuvosos foram 1982, 1983, 1992 e 1998. Usando a classificação obtida através do dendograma em que se obteve os 4 grupos homogêneos, a seguir tem-se a análise dos resultados obtidos.

O primeiro grupo homogêneo (Grupo I) localizado a jusante da bacia contem sete postos pluviométricos em que pode ser observado os maiores índices de anomalia positiva para o ano de 1983 em todas as estações pluviométricas (figura 8), para esse mesmo ano Kousky e Cavalcanti (1984) observaram o avanço ativo dos sistemas frontais na porção sul do Brasil resultante da oscilação positiva do El Niño - Oscilação Sul. Neste ano,1983, se teve a maior média de precipitação na bacia, ainda na mesma Figura, nota-se que o ano de 1985 configura-se como um ano de índice de anomalia negativo. No entanto a figura 8 , também, demonstra outros anos com anomalias positivas como 1983, 1992, 1998 e 2000. 


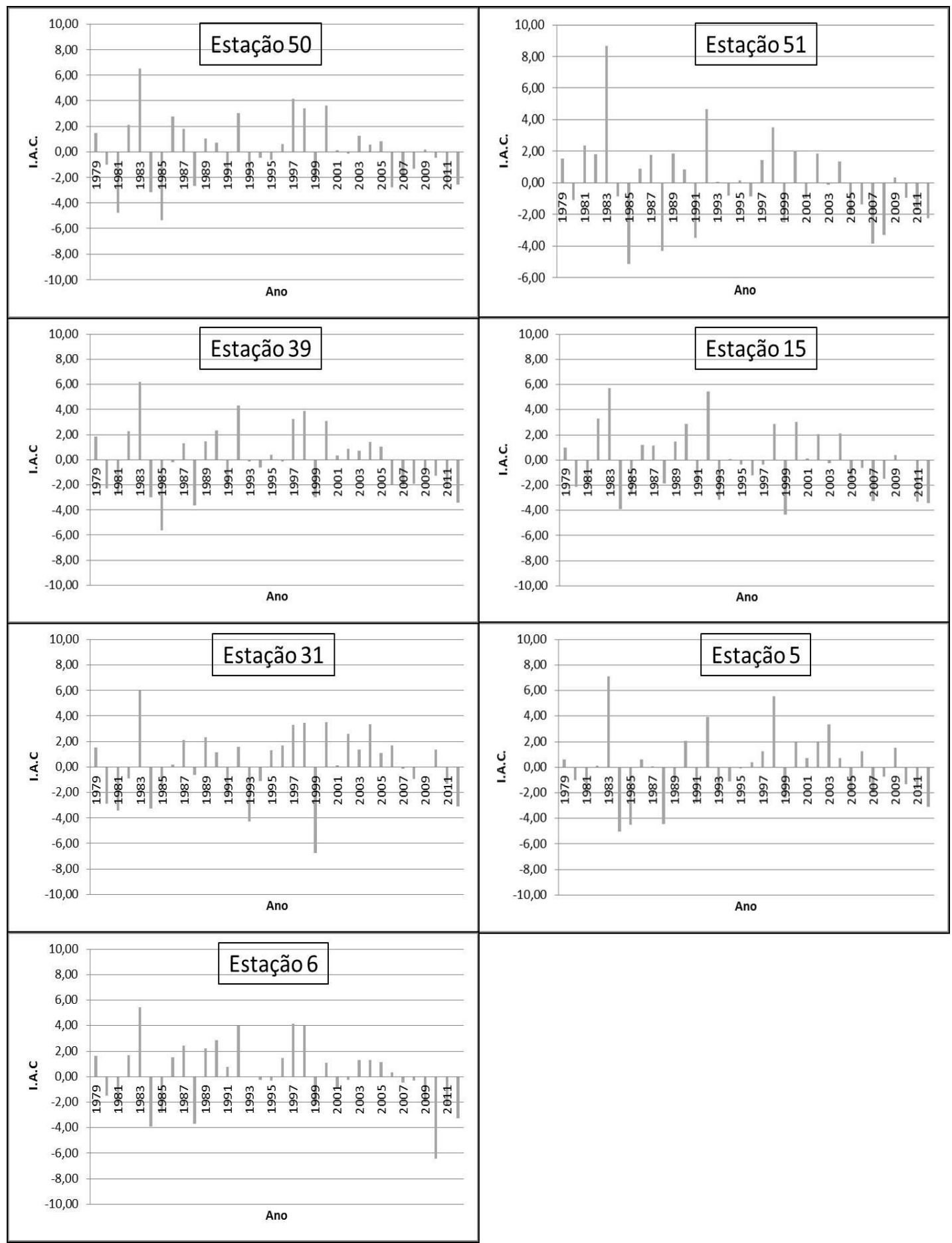

Figura 8 - Índices de anomalia de precipitação para o Grupo I, para o período de 1979 2012.

O Grupo II (figura 9) é constituído de nove estações pluviométricas, que apresentam valores similares. Está localizado em área de transição entre o baixo e o médio Piquiri. Neste grupo observa-se que as anomalias são maiores 
em relação ao Grupo I, evidenciando o ano de 1983 como o mais representativo com índice de anomalia positiva maior que oito para a estação de Xambrê. O ano de 1999 e 2010 foram observados os menores índices de anomalias com valores abaixo de seis.

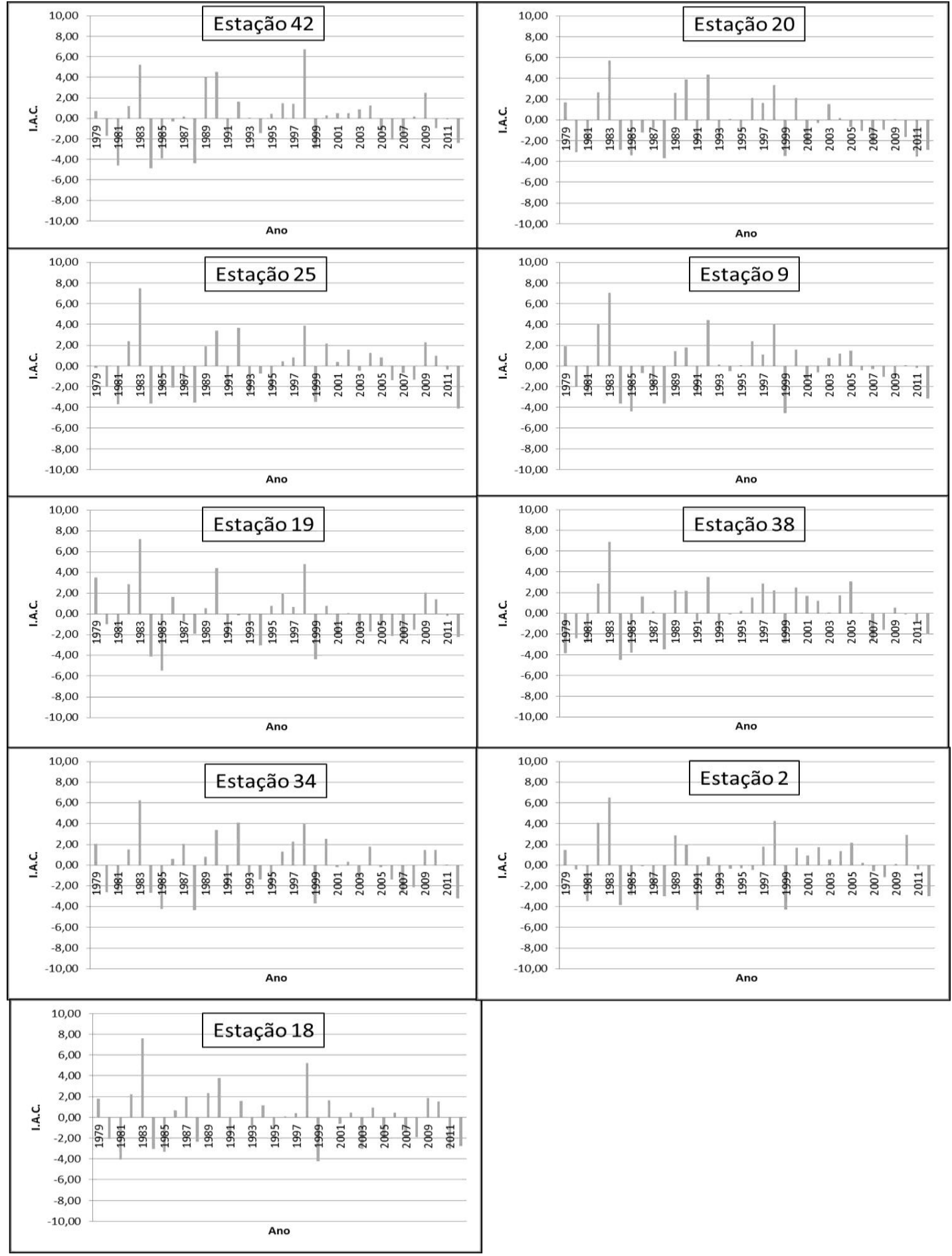

Figura 9 - Índices de anomalia de precipitação para o Grupo II, para o período de 1979 $-2012$. 
$\mathrm{Na}$ figura 10 em que estão representados os valores dos índices de anomalia para o Grupo III, novamente observa-se que o ano de 1983 é aquele cujo índice é maior que oito caracterizando-o, segundo a metodologia de Rooy (1965), como um ano extremamente úmido, seguido dos anos de 1986, 1990 e 1998, ainda de acordo com a classificação do mesmo autor o ano de 1985 para a estação de Bragantina é considerado como extremamente seco com I.A.C. menor que -4 .

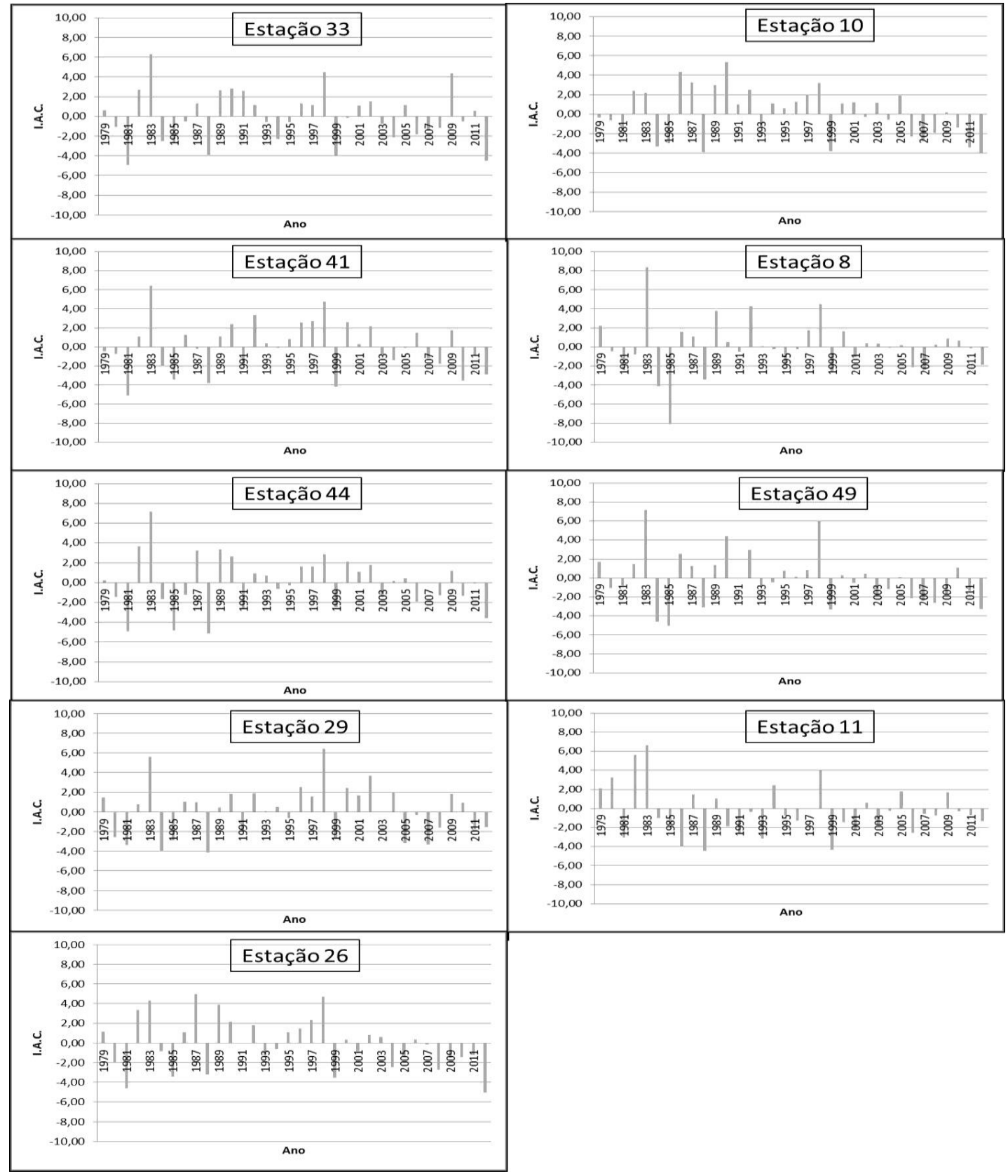

Figura 10 - Índices de anomalia de precipitação para o Grupo III, para o período de 1979- 2012. 
O Grupo IV (figura 11) corresponde às estações da porção centro-sul da bacia. Neste grupo tem-se os anos de 1983 e 1998 com o I.A.C maior que 4 caracterizando com anomalias positivas para todas as estações desse grupo. As anomalias negativas mais significativas para esse grupo ocorreram para o ano de 2012, quando o índice de anomalia de chuva ficou com valores entre - 4 a 6.

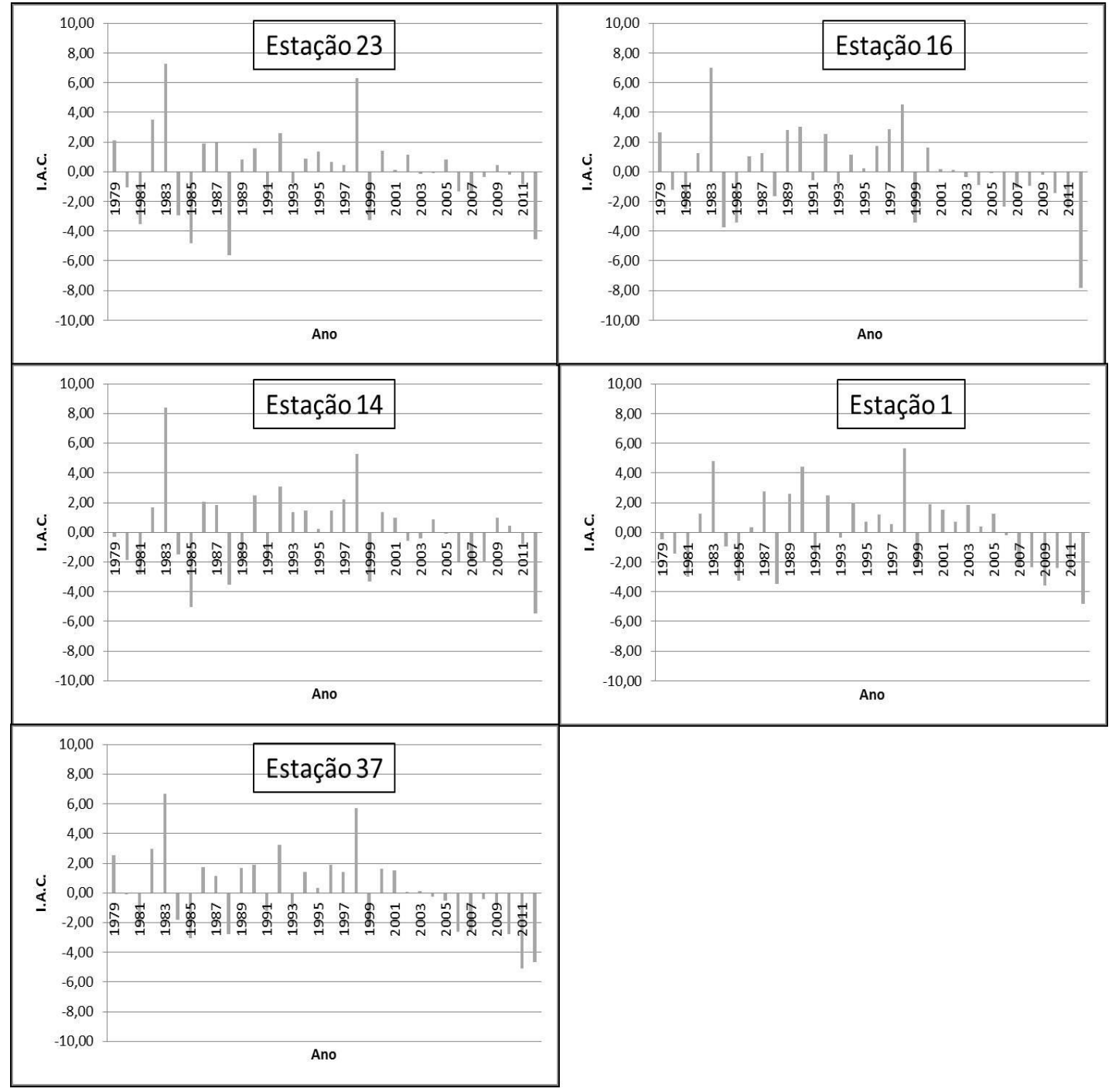

Figura 11 - Índices de anomalia de precipitação para o Grupo VI, para o período de 1979- 2012.

\section{CONSIDERAÇÕES FINAIS}

A bacia hidrográfica do Rio Piquiri apresenta uma definição de períodos secos e períodos chuvosos.

As análises dos dados demonstraram um notável gradiente de precipitação, no qual os menores valores foram observados na porção da foz da bacia, com $1450 \mathrm{~mm}$ de precipitação em média, registrado para o período, 
enquanto os maiores valores, $1950 \mathrm{~mm}$ foram registrados na porção centro-sul e leste da unidade.

Na escala anual, tanto para valores médios de precipitação pluviométrica, quanto para a frequência de dias de chuva, os menores valores, resultando em 81 foram observados na porção do Baixo-Piquiri, ao passo que os maiores valores, 103 dias foram registrados na porção do Alto Piquiri.

Quando realizada a regionalização da precipitação pluviométrica resultaram em quatro grupos homogêneos distintos entre si, em que se puderam observar os valores das anomalias para cada estação de cada grupo, ao qual ficou evidenciado o ano de 1983 com o maior índice de anomalia positiva para a maioria das estações e o ano de 2012 caracterizado como o ano com os menores índices de anomalia negativa, como pode ser visto na figura 11 , onde se lê Estação 14.

Observou-se, portanto, que a espacialização da precipitação pluviométrica fornece um panorama geral das condições do fator chuva, à medida que ficou evidente a influência da orografia para a caracterização da área estudada, em que as áreas a jusante são as que apresentam os menores totais pluviométricos e a porção a montante aquela em que foram percebidos os maiores totais.

\section{REFERÊNCIAS}

ANA (Agência Nacional de Águas). Hidroweb. Séries Históricas. Disponível em: <http://hidroweb.ana.gov.br/> . Acesso em 03 de abril de 2015.

BALDO, M.C. Variabilidade Pluviométrica e a Dinâmica Atmosférica da Bacia do Rio Ivaí. 2006. 153 p. Tese (Doutorado) do Programa de Pós-Graduação em Geografia (Desenvolvimento Regional e Planejamento Ambiental) da Universidade Estadual Paulista, Presidente Prudente, 2006.

BARRELLA, W.; PETRERE JR., M.; SMITH, W.S.; MONTAG, L.F.A. As relações entre as matas ciliares, os rios e os peixes. In: RODRIGUES, R.R. \& LEITÃO FILHO, H.F.Matas ciliares: Conservação e recuperação. EDUSP, $2^{a}$ ed., São Paulo, p.187-207, 2001.

CORREA, M.G.G. Distribuição espacial e variabilidade da precipitação pluviométrica na Bacia do Rio Piquiri - PR. 2013. Dissertação (Mestrado) Faculdade de Filosofia, Letras e Ciências Humanas, Universidade de São Paulo, São Paulo, 2013.

COSCARELLI, R.; CALOIERO, T. Analysis of daily and monthly rainfall concentration in Southern Italy. (Calabria Region). Journal of Hydrology. V. 416 - 417, p 145 - 156, 2012.

GRIMM, A. M. Clima da Região Sul do Brasil. In: CAVALCANTI, I.F.de A. et al. Tempo e clima no Brasil. São Paulo: Oficina de Textos, 2009.

GRIMM, A. M.; FERAZ, S. E. T. Variabilidade sazonal e interanual da precipitação no Estado do Paraná: Efeitos de El Niño e La Niña. SIMPÓSIO BRASILEIRO DE RECURSOS HÍDRICOS, 12., 1997, Vitória. Bases Técnicas para a Implementação dos Sistemas de Gestão de Recursos Hídricos. Vitória, 1997. 1 CD. 
INSTITUTO DE TERRAS, CARTOGRAFIA E GEOCIÊNCIAS (ITCG). Dados e informações geoespaciais temáticos, 2015. Disponível em: $<$ http://www.itcg.pr.gov.br/modules/faq/category.php?categoryid=9 > . Acesso em: 15 de abril de 2015.

INSTITUTO NACIONAL DE PESQUISAS ESPACIAS (INPE). EI Niño. Disponível em: <http://www. http://enos.cptec.inpe.br/> . Acesso em: 20 de abril de 2015.

KOUSKY, V. E. ; CAVALCANTI, I. F. A. Evento El Niño Oscilação Sul: características, evolução e anomalias de precipitação. Ciência e Cultura. São Paulo, v, 36, n. 11, p1188-1199, 1984.

MILANESI, M. A.; GALVANI, E. Efeito Orográfico na Ilha de São Sebastião (Ilhabela/SP). Revista Brasileira de Climatologia, n. 9, p. 68-79, jul/dez, 2011.

PELEGATTI, C. H. G. ; GALVANI, E. Avaliação da precipitação na Serra do Mar SP em eventos de diferentes intensidades e duração. GEOUSP - Espaço e Tempo, São Paulo, n.27, p 147-158, 2010

ROOY, M. P. van. A rainfall anomaly index independent of time and space. Notos, Pretoria, v. 14, p. 43-48, 1965.

SEMA (Secretaria de Estado do Meio Ambiente e Recursos Hídricos). Bacias Hidrográficas do Paraná. Série Histórica. $2^{\mathrm{a}}$ ed. Curitiba, SEMA - Paraná, 2013.

SOUSA, P. Estudo da variabilidade da precipitação no Estado do Paraná associado à anomalia da TSM no Oceano Pacífico. 2006. Dissertação (mestrado) - Universidade Estadual de Maringá. Programa de Pós-graduação em Geografia. Maringá, PR. 2006.

WEYKAMP, F. V. Eventos extremos de precipitação no Sul/Sudeste da América do Sul associados a jatos de baixos níveis. 2006, Dissertação (mestrado em meteorologia) - Instituto de Astronomia, Geofísica e Ciências Atmosféricas. Universidade de São Paulo, São Paulo, 2006 